\title{
Insights on the Regeneration Potential of Müller Glia in the Mammalian Retina
}

\author{
Ahmed Salman ${ }^{1, *(\mathbb{D}}$, Michelle E. McClements ${ }^{1}(\mathbb{D})$ and Robert E. MacLaren ${ }^{1,2}$ \\ 1 Nuffield Department of Clinical Neuroscience, University of Oxford, Oxford OX3 9DU, UK \\ 2 Oxford Eye Hospital, Oxford OX3 9DU, UK \\ * Correspondence: enquiries@eyes.ox.ac.uk
}

Citation: Salman, A.; McClements, M.E.; MacLaren, R.E. Insights on the Regeneration Potential of Müller Glia in the Mammalian Retina. Cells 2021, 10, 1957. https://doi.org/10.3390/ cells10081957

Academic Editor: Alexander E. Kalyuzhny

Received: 19 June 2021

Accepted: 26 July 2021

Published: 31 July 2021

Publisher's Note: MDPI stays neutral with regard to jurisdictional claims in published maps and institutional affiliations.

Copyright: (c) 2021 by the authors. Licensee MDPI, Basel, Switzerland. This article is an open access article distributed under the terms and conditions of the Creative Commons Attribution (CC BY) license (https:// creativecommons.org/licenses/by/ $4.0 /)$.

\begin{abstract}
Müller glia, the major glial cell types in the retina, maintain retinal homeostasis and provide structural support to retinal photoreceptors. They also possess regenerative potential that might be used for retinal repair in response to injury or disease. In teleost fish (such as zebrafish), the Müller glia response to injury involves reprogramming events that result in a population of proliferative neural progenitors that can regenerate the injured retina. Recent studies have revealed several important mechanisms for the regenerative capacity of Müller glia in fish, which may shed more light on the mechanisms of Müller glia reprogramming and regeneration in mammals. Mammalian Müller glia can adopt stem cell characteristics, and in response to special conditions, be persuaded to proliferate and regenerate, although their native regeneration potential is limited. In this review, we consider the work to date revealing the regenerative potential of the mammalian Müller glia and discuss whether they are a potential source for cell regeneration therapy in humans.
\end{abstract}

Keywords: Müller glia; reprogramming; retinal regeneration; regeneration potential; stem cells; proliferation; differentiation

\section{Introduction}

Vision is often reported as the sense most adults (88\%) would least like to lose [1]. Blindness can result from injury or disease, with retinal disease caused by loss or damage to the highly organised laminar structure of specialised neural cells at the back of the eye. Diseases such as retinitis pigmentosa, age-related macular degeneration, diabetic retinopathy and glaucoma can lead to blindness due to the loss of function of one or more of these specialised cell types. There are numerous strategies for attempting to prevent or delay sight loss and even to restore vision in those with no light perception. The treatment approach taken will depend on the stage and origin of sight loss, but current strategies include cell transplantation [2], gene supplementation [3], gene correction [4], optogenetics [5] and prosthetic devices [6]. Whilst these strategies are showing promising signs of safety and efficacy and are rapidly evolving and improving, they require surgical intervention for the delivery of viral vectors and/or reprogrammed cells and implants. A less invasive strategy for retinal regeneration could be for remaining cell types of the retina to initiate repair.

The idea of a self-renewing retina might seem unfeasible, but it is not unprecedented; zebrafish show a remarkable ability to regenerate the retina after injury [7-9]. This regeneration potential stems from one cell type in the retina, the Müller glia, which are astrocyte-like radial cells that play a pivotal role in maintaining retinal structure and homeostasis and are considered to be the main glial cells in the retina. In zebrafish, Müller glia undergo reprogramming events in response to injury and acquire stem cell characteristics and proliferate to progenitor cells, which leads to retinal repair [10-15]. Although this regeneration potential is common for all vertebrates, it is, however, absent in mammalian systems for unknown reasons. Gaining more understanding of the mechanisms of the 
regeneration potential in fish may help unlock the reasons why mammalian cells lack this phenomenon and how we might encourage it.

This review will consider the responses of Müller glia to retinal injury in mammals and the signalling mechanisms underlying their reprogramming and regeneration potential.

\section{Müller Glia Anatomy and Function}

The function of the retina is to convey light signals to the brain. The photoreceptor cells respond to light, triggering a phototransduction cascade that passes through the bipolar cells, then on to the retinal ganglion cells that converge into the optic nerve, which carries the signal to the brain. Horizontal cells enable interconnections of multiple photoreceptors and bipolar cells, whilst amacrine cells are the interneurons between bipolar cells and ganglion cells (Figure 1). These cell types are critical for the conductance of light signals to the brain but the neural retina also contains three types of glial cells: microglia and two types of macroglia, astrocytes and Müller cells, with the latter considered the main glial cell type in the retina [16]. These glial cells provide structure and functional support to the retina.

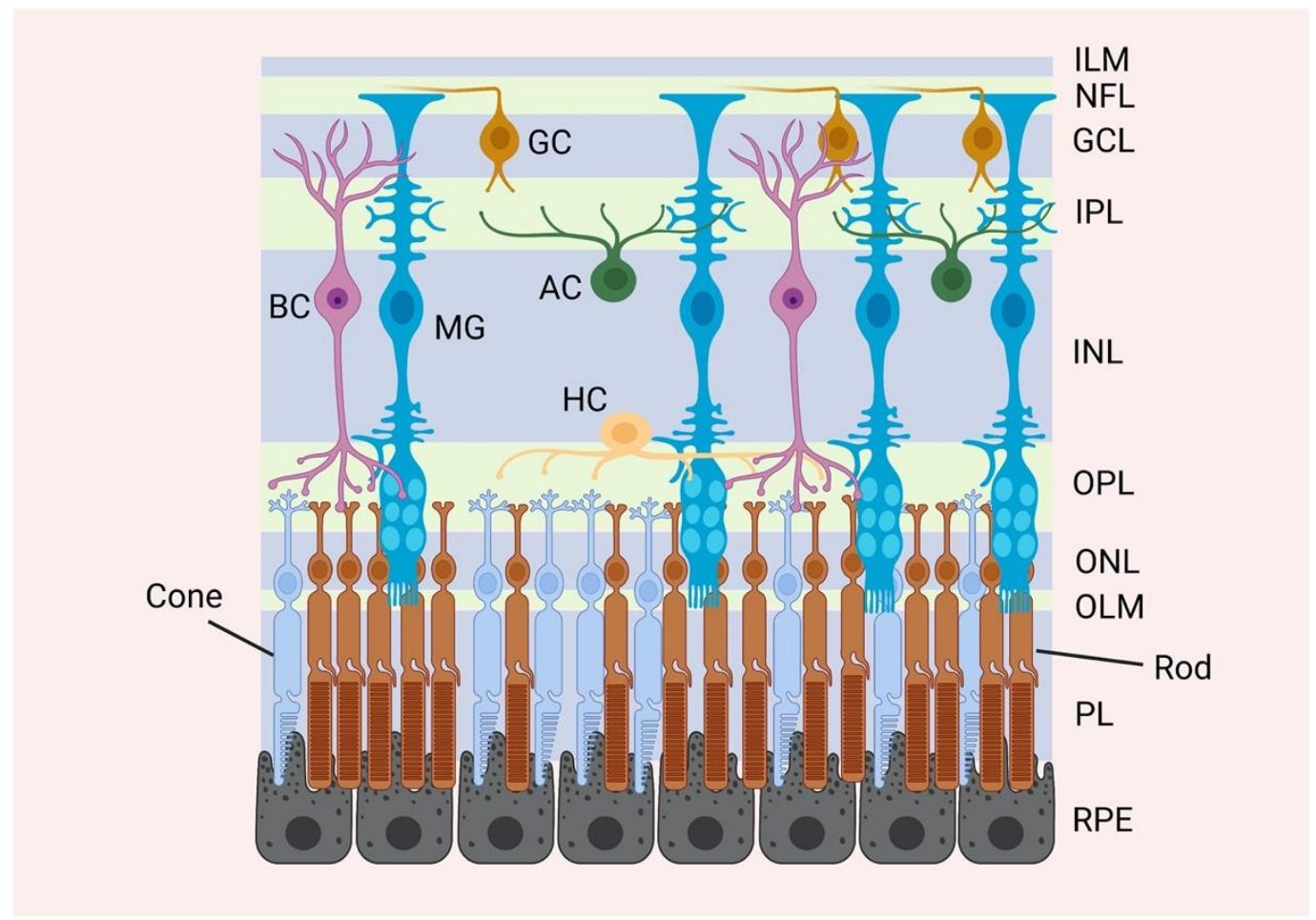

Figure 1. The mammalian retinal anatomy. A representative illustration of the major retinal layers and cell types. The mammalian retina is divided into 3 main laminar layers: the outer nuclear layer (ONL), the inner nuclear layer (INL) and the ganglion cell layer (GCL). There are six different retinal neuronal cell types and one glial cell type distributed within the nuclear layers: the rod and cone photoreceptor cell bodies are located in the ONL, whereas the cell bodies of the bipolar (BC), horizontal (HC), amacrine (AC) and Müller (MG) cells are located in the GCL. The cell bodies of the ganglion cells (GC) are located in the GCL. The processes of the different cells are extended into two plexiform layers. Processes from the photoreceptor cells are extended into the outer plexiform layer (OPL) to form synapses with the retinal neurones. Processes from the bipolar, horizontal, amacrine as well as Müller cells are extended into the inner plexiform layer (IPL). The axons of the ganglion cells are directed into the optic nerve through the nerve fibre layer (NFL). Müller glia span the length of the retina from the outer to the inner limiting membranes (OLM and ILM, respectively).

Müller glia are radial shaped cells that span the entire thickness of the neural retina from the outer to the inner limiting membranes (OLM and ILM, respectively) (Figure 1). They share a multipotent origin with neurones in the retinal neuroepithelium [17]. The process of originating Müller glia is not well understood but involves several signalling 
pathways such as Notch, retinal homeobox protein Rx (RAX) and Janus kinase (JAK) signalling [18-22]. Müller glia are developed at later stages of retinal development as revealed by ${ }^{3} \mathrm{H}$-Thymidine labelling studies [23]. The retinal ganglion cells are the first to be born, followed shortly by the horizontal, cone photoreceptors and displaced amacrine cells. At later stages, the amacrine, bipolar and Müller cells appear.

Müller cell processes make contact with all retinal neurones and blood vessels supporting the overall retinal structure and monitor homeostasis [24]. Their somata lie in the inner nuclear layer (INL) of the retina with processes that radiate from the soma in opposite directions, spanning the thickness of the entire retina and making contact with both the inner limiting membrane (ILM) and outer limiting membrane (OLM), where they form tight junctions with the photoreceptor layer [16]. Their lateral processes expand into the inner and outer plexiform layers (IPL and OPL, respectively), where they make sheaths around the synapses in these layers.

The unique anatomy of Müller glia means they are well-positioned to monitor retinal homeostasis and contribute to the overall structure of the retina. They provide homeostatic, metabolic and structural support to retinal neurones, regulate ion and water homeostasis and maintain the blood-retinal barrier [24]. Müller cells also impact the synaptic activity in the retina by recycling neurotransmitters including glutamate and gamma-Aminobutyric acid (GABA) [25-27]. The uptake of the neurotransmitter glutamate by the glutamateaspartate transporter (GLAST) is known to be important in regulating levels in the inner and outer plexiform layers. This prevents the spread of glutamate beyond the synapses, which ensures a fine resolution and prevents glutamate toxicity $[25,28]$. Furthermore, GABA is converted to glutamate after uptake by Müller cells and is then converted to glutamine by a glutamine synthase, which is localised specifically in Müller cells [25]. The neurotransmitter recycling process continues with glutamine released by Müller glia to be taken up by neurones as a precursor to producing GABA and glutamate. Müller glia's involvement in regulating the synaptic connectivity in the inner retina has been confirmed by both pharmacological blockade and downregulation of glutamine synthase, resulting in neuronal dysfunction in the retina $[25,29]$.

Functions of Müller glia therefore impact, directly or indirectly, the neuronal activity of the retina. These cells also control the release of potassium ions across the intra- and extracellular spaces in the retina, preventing neuronal hyperexcitation that can be caused by an excess release of potassium ions [16].

The clearance of water from retinal tissue also appears to be mediated by Müller cells. The uptake of glucose, by the retinal epithelial cells, causes water influx from the blood that accumulates in the retina, coupled with water production from the oxidative degradation of glucose. There is also pressure-induced water influx by the vitreous, all of which causes water accumulation in the retina. Müller glia mediate an osmotically driven water clearance through ionic shift across the transmembrane facilitated by aquaporin- 4 channels [24,30], in particular potassium [31], which redistributes excess water out of the retina.

These functions are a snapshot of the roles undertaken by the Müller glia to provide a general understanding of the importance of these cells in maintaining the health and function of the retina. Other functions include the anti-oxidative support of photoreceptors and retinal neurones [32], removal of $\mathrm{CO}_{2}$ and regulation of the extracellular $\mathrm{pH}$ [33], maintenance of the blood-retinal barrier $[34,35]$ and regulation of the retinal blood flow [36]. Further details of such functions can be found in comprehensive reviews of these cell types.

\section{Müller Glia Response to Injury in Mammals}

Unlike in zebrafish, birds and amphibians, where the retina has spontaneous regeneration potential driven by Müller glia to repair the retina upon injury or disease [7-9,37], in the mammalian retina such regeneration potential is limited. Thus, human retinal disease often leads to a permanent loss of vision and blindness. Although Müller glia in the mammalian retina harbour stem cell characteristics [38], they are unable to regenerate the retina despite showing the ability to acquire characteristics of retinal neurons in vitro when 
cultured with selective growth factors that induce differentiation [39-41]. This limited capacity of retinal repair in the mammalian retina is also evident in vivo, and it is currently unknown whether factors or molecules induced during development or disease are halting this regeneration capacity in Müller glia.

Several types of cells in the mammalian retina, one of which is Müller cells, have been shown to exhibit neurogenic potential, the others being cells of the ciliary margin and the retinal pigment epithelium (RPE) [42-45]. Müller cells in mammals are normally quiescent; however, they are activated upon stress or injury in a process known as "reactive gliosis", where they change morphology and undergo a shift in expression profile, dedifferentiation, migration and proliferation [46,47]. Reactive gliosis is beneficial to neurones as it prevents glutamate neurotoxicity, as noted earlier, as well as releasing a range of factors that prevent cell death [47]. These events somehow resemble processes that occur during retinal regeneration and repair in fish and birds, but with an absence of neuronal regeneration and retinal repair $[46,47]$. Mammalian Müller cells are therefore able to undergo gliosis, but seem unable to differentiate into retinal neurons. There are number of key events during Müller glia reprogramming in zebrafish that represent a potential intervention window in the mammalian systems to stimulate neuronal regeneration (Figure 2).

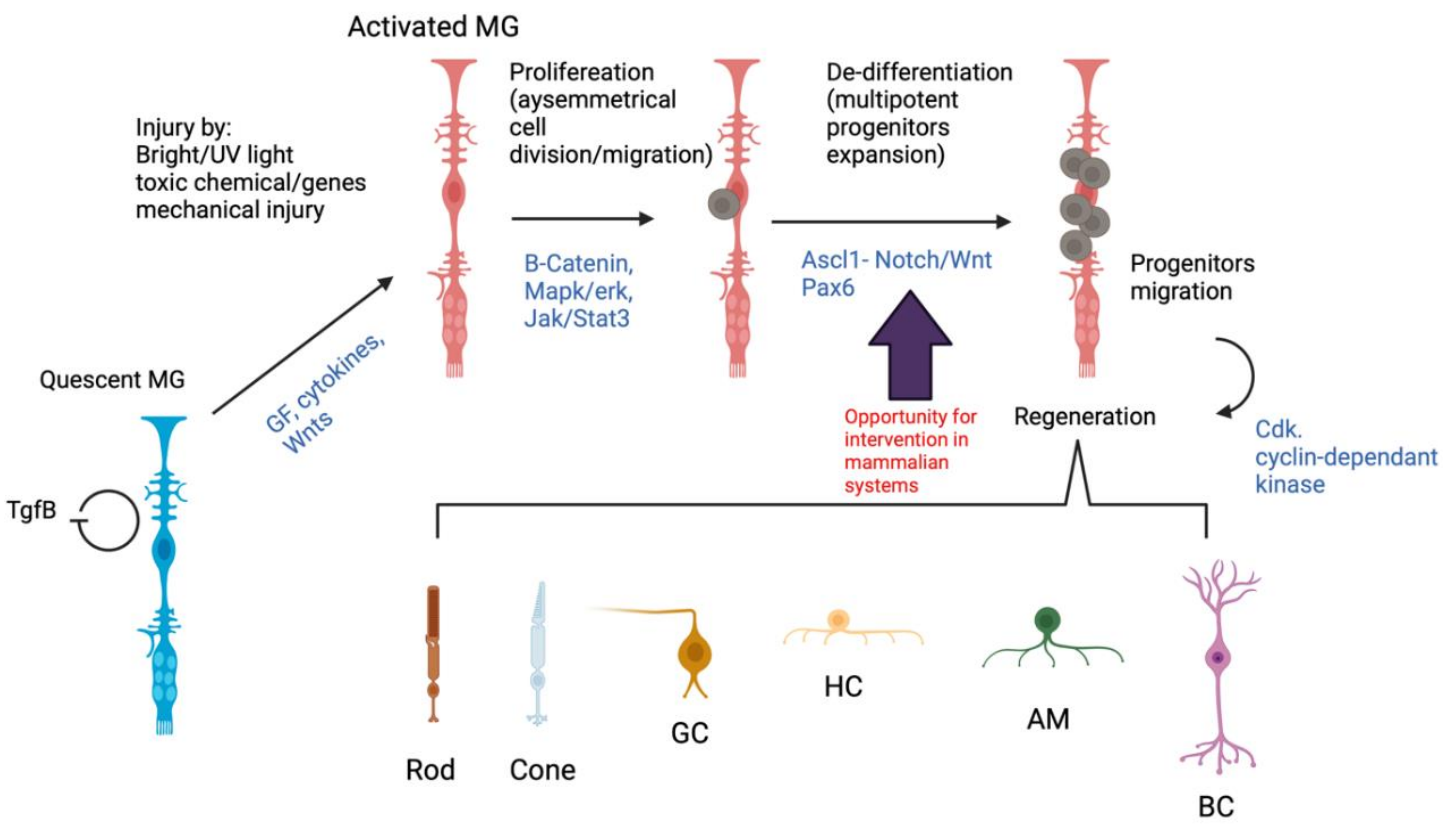

Figure 2. Müller glia regeneration-associated molecular cascades in zebrafish. A hypothetical pathway representing Müller glia activation in response to injury and the sequence of events that leads to retinal regeneration in zebrafish (black text). Müller glia are quiescent in absence of injury, a process regulated by TgfB/Smad pathway. Upon injury, Müller glia are encouraged start reprogramming and enter the cell cycle in a complex of events involving B-catenin, Mapk/erk and Jak/Stat3 signalling pathways, which stimulate proliferation. These pathways stimulate injury-dependant Ascl-1 expression, which regulates the generation of Müller glia-l-derived progenitor cells (MGPCs). Those sequences of events also occur in mammalian systems. However, the MGPCs in zebrafish retina expand and migrate to regenerate the injured retina. This regeneration potential is inefficient in mammalian systems. Intervention at key steps in the zebrafish Müller glia reprogramming might stimulate the regeneration potential in mammalian Müller glia (purple arrow).

The limited, or lack of, ability of Müller cells to differentiate into retinal neurones has been challenged several times. Evidence from in vitro and in vivo studies has shown that Müller cells can undergo reprogramming and produce new bipolar and photoreceptor cells in response to N-Methyl-D-aspartic acid (NMDA) [48] or amacrine cells after NDMAinduced damage and growth factor treatment [49]. Differentiation into retinal neurones and photoreceptors has also been shown after growth factor treatment [38,50-53]. However, damage by intense light exposure did not seem to promote Müller cell proliferation [54]. 
Whilst there are indications of the regeneration potential of Müller glia, the current data are inconclusive in the extent to which this occurs or indeed how to exploit it with the mechanisms still largely unknown. Neuronal explants present an environment where neuronal loss occurs spontaneously, which triggers reactive gliosis [55]. Müller cells in retinal explants are not quiescent anymore and dedifferentiate/reprogram to acquire stem cell characteristics and start proliferation and neural regeneration. When growth factors that trigger Müller cells' activation are introduced, more than half of the cell population starts proliferating, breaking the quiescent state [55]. NMDA-induced retinal damage of the mouse retina in combination with Epidermal Growth Factor (EGF) treatment is one of the most potent methods to stimulate Müller glia proliferation [49]. The Müller glia proliferation stimulated by NMDA and EGF treatment involves mitogen-activated protein kinase (MAPK), bone morphogenesis protein (BMP), and phosphoinositide 3kinase (PI3K) signalling pathways [56]. During the early stages of retinal development in the mammalian retina when Müller glia are proliferating, the EGF receptor (EGFR) is upregulated. However, when Müller glia stop proliferating and become quiescent, EGFR expression is downregulated and this decrease in expression is accompanied by the overexpression of transforming growth factor-beta (TGF-B) signalling, which appears to have a suppressive effect on the proliferation of Müller cells postnatally $[57,58]$.

Interestingly, the subretinal delivery of non-toxic doses of glutamate has been shown to stimulate Müller glia proliferation and neural regeneration in vivo [59]. This suggests that, under the right conditions, Müller glia do have the potential to reprogram and regenerate for retinal repair.

During retinal reprogramming in fish, the upregulation of the Achaete-scute homolog 1 (Ascl1) gene has particular importance in the reprogramming of Müller cells into neural progenitors [7-9,60]. Interestingly, the mouse Ascl1 was not upregulated in NMDA-induced damage of the retina [49], which might go some way towards explaining the poor regenerative capacity of Müller cells in mammals. However, the overexpression of Ascl1 is correlated with retinal damage in young mice [55], suggesting there is a higher potential of Müller cell reprogramming in young mice, where Müller glia are still proliferating [55,56]. In addition, the overexpression of Ascl1 in vitro was sufficient to activate neurogenic reprogramming in Müller glia. This was also observed ex vivo in retinal explants, in which the overexpression of Ascl1 caused the de-differentiation of Müller glia and expression of the bipolar marker protein kinase alpha (PKCa) [61].

\section{Current Understanding of the Regeneration Potential of Müller Glia in Mammals}

Certain signalling pathways such as Wnt/B-catenin [51,52], sonic hedgehog [62], epidermal growth factor (EGF)-EGF receptor (EGFR), glutamate and Ascl1-dependent signalling pathways [61] (Table 1), are known to trigger proliferative events and neural regeneration by Müller glia in the injured mammalian retina.

Historically, the regenerative potential of retinal glial cells was investigated by MacLaren et al. [63], where it was shown that the glial scars caused by surgical lesions in humans are different than other scars in the nervous system, in which a regrowth and reconnection of regenerating axons was observed. Eventually, it has been revealed that the regrowth was in fact of retinal ganglion cells.

Regarding the role of Ascl1 in mammalian Müller glia, evidence of chromatin modification has emerged, showing an increased capacity of neuronal regeneration of Müller cells after retinal injury when both Ascl1 and histone deacetylase inhibitor (HDAC) were overexpressed [64]. This suggests epigenetic modifications might hold a key role in modulating Müller glia regeneration capacity. Just like in fish, Müller glia acquire stem cell characteristics and start expressing pluripotent genes upon activation [10]. 
Table 1. Factors affecting Müller glia regeneration in mammals.

\begin{tabular}{|c|c|c|c|c|}
\hline $\begin{array}{c}\text { Signalling } \\
\text { Pathway/Factor }\end{array}$ & Function & Species Tested & $\begin{array}{l}\text { Effect on Müller } \\
\text { Glia Regeneration }\end{array}$ & References \\
\hline Ascl1 & Transcription factor & Birds, rodents & Stimulates & {$[49,55,56]$} \\
\hline BMP-SMAD & $\begin{array}{l}\text { Signalling pathways } \\
\text { activated by a secreted factor } \\
\text { (BMP) when binding to a } \\
\text { transcription factor (SMAD) }\end{array}$ & Rodents & Stimulates & {$[56]$} \\
\hline EGF/EGFR & $\begin{array}{l}\text { Signalling pathways } \\
\text { activated by a secreted factor } \\
\text { (EGF) when binding to its } \\
\text { receptor (EGFR) }\end{array}$ & Rodents & Stimulates & {$[49,57,58]$} \\
\hline Glutamate & Neurotransmitter & Rodents & Stimulates & [59] \\
\hline FGF2-FGFR-MAPK & $\begin{array}{l}\text { Secreted factor (FGF2) } \\
\text { binding to its receptor } \\
\text { (FGFR) to activate a } \\
\text { signalling pathway (MAPK) }\end{array}$ & Birds, rodents & Stimulates & {$[57,65-68]$} \\
\hline Delta-Notch & $\begin{array}{l}\text { Signalling cascade activated } \\
\text { by a transmembrane ligand } \\
\text { (Delta) binding to its receptor }\end{array}$ & Birds, rodents & Stimulates & {$[20,49,65]$} \\
\hline Pax6 & Transcription factor & Birds, rodents & Unknown & {$[49,69]$} \\
\hline Insulin-IGF1-PI3K & $\begin{array}{l}\text { Secreted factor (FGF2) } \\
\text { binding to its receptor } \\
\text { (FGFR) to activate a } \\
\text { signalling pathway (MAPK) }\end{array}$ & Birds, rodents & Stimulates & [66-68] \\
\hline $\mathrm{SHH}$ & Secreted factor & Rodents & Stimulates & {$[62,70]$} \\
\hline TGF-B & Secreted factor & Rodents & Inhibits & {$[52,57,58]$} \\
\hline Wnt/B-catenin & Signal transduction pathway & Rodents & Stimulates & {$[51,52,71,72]$} \\
\hline
\end{tabular}

Interestingly, the promoter of Ascl1 and other pluripotent genes such as LIN28, HBEGF, SOX2 and OCT4 maintain a hypomethylated state that makes them more accessible, indicating that Müller glia might be acting as endogenous stem cells. To further reiterate the role of epigenetic modification, it was recently shown that targeted destruction of polypyrimidine tract-binding proteins (PTBs), which are micro-RNA coding proteins, results in the dedifferentiation of Müller glia into retinal ganglion cells in vivo [64]. In this study, the Ptbp 1 mRNA was targeted by CRISPR technology using Cas-Rx recombinase and delivered to the retina via a viral vector. The differentiation of Müller glia to ganglion cells was then assessed and the visual function of mice was also examined to evaluate the replenishment of the ganglion cell population in the retina. Research on the inhibition of micro-RNAs such as miR-9 and miR-124, as well as transcription factors involved in epigenetic modifications such as HDAC and the repressor element1-silencing transcription factor (REST), is becoming increasingly interested in understanding Müller glia regeneration potential. Recently, it has been suggested that micro-RNAs, such as miR-25 and miR-124, play an important role in Müller glia neurogenic potential in mice by inducing the expression of Asl1, leading to the conversion of mature Müller glia into neural progenitor cells [73]. Another recent study has shown that the inhibition of miR-28 upregulates CRX, a photoreceptor-specific marker, which leads to the transdifferentiation of Müller glia progenitor cells into photoreceptors [74]. Understanding the nature of epigenetic modifications might reveal key mechanisms of the Müller glia regeneration potential, or the lack of it.

Similar to the role of Ascl1 and Notch signalling in activating Müller cells, the Wnt/Bcatenin signalling pathway also activates Müller glia and promotes proliferation by making them enter the cell cycle and promote the production of Müller glia progenitor cells (MGPCs) [51]. Interestingly, the activation of the Wnt pathway alone is sufficient to 
stimulate Müller glia to re-enter the cell cycle and proliferate [72]. The same study also showed that Wnt signalling is dependent on B-catenin signalling and that each pathway is individually capable of stimulating Müller cell proliferation. Unfortunately, the number of differentiating Müller cells in the above study was limited. However, another interesting study by Yao et al., 2018 showed that Müller glia were able to differentiate in vivo after the activation of the Wnt/B-catenin signalling pathway to stimulate cell proliferation. This was followed by the promotion of differentiation by the photoreceptor differentiation genes Otx2, Crx and Nrl in a mouse model of congenital blindness [71]. Another study by Angshumonik et al., 2016 revealed the relationship between Wnt/B-catenin and TGF-B signalling pathways in modulating Müller glia transdifferentiation into photoreceptors in vitro [52], which draws attention to the active role that the Wnt/B-Catenin might be acting on the regulation of Müller glia reprogramming in the mammalian retina.

Müller glia activation can occur by cell-to-cell fusion. For example, the activation of the Wnt/B-catenin signalling pathway occurred following the transplantation of iPSCs into NMDA-treated mouse retina. This coincided with the fusion of the cells with Müller, amacrine and ganglion cells that then dedifferentiated and regenerated the amacrine and ganglion cells [75]. In contrast, the downregulation of the Wnt/B-catenin signalling pathway (TGF-B signalling factors) resulted in the differentiation of Müller glial cell cultures with stem cell characteristics into photoreceptors [52].

When haematopoietic stem and progenitor cells (HSPS) were transplanted in the mouse retina, they fused only with Müller cells and the hybrid cells acquired stem cell characteristics and differentiated into photoreceptors [76]. The molecular mechanisms of the cell-to-cell fusion activation of Müller glia discussed are unknown and lack convincing in vivo functional tests. More research is required in this area to better understand the process and indeed to determine what purpose it might serve.

The role of the Sonic hedgehog (Shh) signalling pathway in Müller glia reprogramming has also been investigated. It has been suggested that the Shh pathway promotes Müller glia proliferation and stem cell characteristics in the injured rat retina [62]. Recently, the role of the Shh pathway in Müller glia transdifferentiation into photoreceptors was described [70]. Both Angbohang et al. (2016) and Gu et al. (2017) showed evidence of direct transdifferentiation of Müller glia into photoreceptors using different signalling pathways, Wnt/B-catenin and Shh, respectively, which opens up the possibility of modulating Müller glia reprogramming in retinal repair. However, both studies were in vitro; therefore, this transdifferentiation phenomenon in Müller glia still needs to be translated in vivo.

There is an argument that cellular metabolism, which refers to a set of chemical reactions in the cell that affect cell fate decisions, plays a role in Müller glia reprogramming. Although the transition from glycolysis, which stem cells use as a source of energy during pluripotency stages, to oxidative phosphorylation in the mitochondria during differentiation is well documented in the literature $[77,78]$, its relationship with Müller cell reprogramming and differentiation is somehow indirect. However, cellular metabolism might still play a role in the molecular cascade during Müller cells' differentiation, but whether that role is a cause or a consequence of differentiation is still unclear.

There are several other potential factors discussed in the literature on Müller glia reprogramming in mammals, including the regulation of the immune microenvironment, the different subtypes of Müller cells [16] and factors limiting Müller glia reprogramming in mammals, such as the complexity of the mammalian system and other evolutionary events that might halt the regenerative potential of Müller glia in mammals. Similar to the discussion about cellular metabolism, since it involves a multidisciplinary event, their direct involvement in Müller glia reprogramming is unclear. For example, the activation of the immune cells, such as microglia, upon injury is a systemic event and therefore it is hard to conclude its direct effect on the reprogramming of Müller glia.

The field of Müller glia-mediated retinal regeneration is very dynamic (fast-moving) and there has been a number of new developments in the field. Most of the recent developments were reported in either cold-blooded or warm-blooded vertebrates, some of 
which investigated molecular pathways that may improve the current understanding of the reprogramming of Müller glia in mammals. For example, a recent study by Palazzo et al. (2019) investigated the role of the Nuclear Factor Kappa B (NF-kB) pathway in Müller glia reprogramming in chick embryos, which showed that a component of the NF-kB pathway expressed by Müller cells, inhibits the reprogramming of Müller glia into retinal neurons [79], providing targets that can potentially be responsible for the lack of regeneration of mammalian Müller cells into retinal neurones.

\section{Clinical Applications of Reprogrammed Mammalian Müller Glia}

Clinical applications of reprogrammed Müller glia depend on the ability to successfully induce adult Müller glia to regenerate the retina. In mammalian systems, the regenerative potential of Müller glia is inefficient and fails to regenerate retinal neurones [49,69]. This makes it particularly difficult to study the mechanisms of mammalian reprogramming of Müller glia in vivo. Hence, there is a need for a model system to recapitulate retinal specific disease and study retinal development ex vivo. The reprogramming of adult somatic cells into induced pluripotent stem cells (iPSCs) has revolutionised regenerative medicine [80]. One promising approach is the reprogramming of adult Müller glia into iPSCs. Recently, a study by Slembrouck-Berc et al. demonstrated that Müller glia-derived iPSCs can be reprogrammed to acquire stem cell characteristics and differentiate into retinal pigment epithelial cells (RPE) and retinal organoids that harbour multipotent progenitors [81], which are able to differentiate into all major retinal neurones. Another study by Chung et al. and colleagues explored a new methodology of differentiating Müller glia from human embryonic stem cells (hESCs) by promoting the Notch signalling pathway [82]. Another example of understanding the mechanisms of Müller glia reprogramming is the use of ex vivo routes, which helps investigating the molecular queues behind a potential Müller glia regeneration in the mammalian systems. The development of ex vivo models not only helps understating the molecular mechanisms behind the lack of Müller glia regeneration in mammals, as the generation of differentiated Müller glial cells from iPSCs or hESCs can help future therapeutics such as gene editing or drug development using patient-derived glial cells.

In mammalian systems, differentiated retinal neurones do not have the ability to re-enter the cell cycle and divide like other cell types in the body. Injury to the retina that results in neuronal death often leads to vision loss due to the inability to replace lost neurones in the injured area. Other species, such as teleost fish (zebrafish), have a remarkable ability to regenerate the injured retina due to the efficient regeneration potential of their Müller glia [7-9]. Despite the considerable similarities between the mammal and zebrafish retina, the mammalian Müller glia fail to regenerate into retinal neurons in response to injury and their regeneration potential is restricted. Instead of dedifferentiating and initiating regeneration events, they experience reactive gliosis, which often involves cell proliferation and scar formation, failing to initiate regeneration [47]. The change in morphology and gene expression profile that the mammalian Müller glia undergo in response to injury fails to reprogram the cells into all major retinal neurons. Nevertheless, the ability of the mammalian Müller glia to upregulate genes associated with retinal stem cells and adopt stem cell characteristics [38,39,41] suggests that the mammalian Müller glia have the capacity to regenerate into retinal neurones under the right circumstances. Due to the quiescent nature of Müller cells, the process of activating them often involves retinal injury and the introduction of growth factors that stimulate differentiation. This injury certainly causes cell death and the release of apoptotic factors, which is perhaps unfavourable in mammalian systems. It is possible that future strategies to stimulate Müller glia in mammals involving no injury to an affected retina, such as introducing substances like glutamate [59], or activating signalling pathways that help their stimulation without causing injury such as Wnt or Notch signalling pathways [52,83], might help with initiating molecular cascades to stimulate regeneration. 


\section{Future Prospects}

Retinal degeneration often results from cell death within the retina causing permanent sight loss and blindness. The idea of self-renewal potential within the retina is therapeutically appealing, especially with a transdifferentiation phenomenon to replace other cell types that die as a result of a disease. Müller glia possess a regeneration potential in fish in which the injured retina can self-repair. However, whilst the mammalian Müller glia can acquire stem cell characteristics, their regeneration potential is limited. Progress made in understanding the molecular mechanisms in the regeneration of Müller glia in fish has helped understand this lack of regeneration and repair in mammals. Further investigations will increase understanding of the mechanisms involved, including understanding the role of epigenetic modifications in Müller glia reprogramming.

Intrinsic mechanisms involved in regulating Müller glia's response to injury might differ significantly between fish and mammals, but insights may help us exploit native mammalian Müller glia and encourage regeneration in favour of stem cell transplantation approaches. The transdifferentiation of Müller glia might not be an event solely initiated by one cell type; other cells might play a role by interacting with Müller glia and help to activate them, preparing the right environment and cellular events that modulate Müller glia reprogramming. Gaining more understanding of the regenerative potential of Müller glia in retinal repair will certainly be a game-changer in future therapeutic strategies in ocular disease.

Author Contributions: A.S. carried out the literature review research, designed the figures and wrote the original manuscript. M.E.M. and R.E.M. contributed to writing and revision process and agreed to the published version of the manuscript. All authors have read and agreed to the published version of the manuscript.

Funding: Oxford NIHR Biomedical Research Centre.

Institutional Review Board Statement: Not applicable.

Informed Consent Statement: Not applicable.

Data Availability Statement: Not applicable.

Acknowledgments: The figures were created with BioRender.com, accessed on 16 May 2021. We thank Ariel Kantor for editing and proofreading the manuscript.

Conflicts of Interest: The authors declare no conflict of interest.

\section{References}

1. Enoch, J.; McDonald, L.; Jones, L.; Jones, P.; Crabb, D.P. Evaluating Whether Sight Is the Most Valued Sense. JAMA Ophthalmol. 2019, 137, 1317-1320. [CrossRef] [PubMed]

2. Singh, M.S.; Park, S.S.; Albini, T.A.; Canto-Soler, M.V.; Klassen, H.; MacLaren, R.E.; Takahashi, M.; Nagiel, A.; Schwartz, S.D.; Bharti, K. Retinal stem cell transplantation: Balancing safety and potential. Prog. Retin. Eye Res. 2020, 75, 100779. [CrossRef] [PubMed]

3. Trapani, I.; Auricchio, A. Has retinal gene therapy come of age? From bench to bedside and back to bench. Hum. Mol. Genet. 2019, 28, R108-R118. [CrossRef]

4. Kantor, A.; McClements, M.E.; MacLaren, R.E. CRISPR-Cas9 DNA Base-Editing and Prime-Editing. Int. J. Mol. Sci. 2020, 21, 6240. [CrossRef]

5. McClements, M.E.; Staurenghi, F.; MacLaren, R.E.; Cehajic-Kapetanovic, J. Optogenetic Gene Therapy for the Degenerate Retina: Recent Advances. Front. Neurosci. 2020, 14, 570909. [CrossRef]

6. MacLaren, R.E. Electronic retinal implant surgery. Eye 2017, 31, 191-195. [CrossRef] [PubMed]

7. Sherpa, T.; Fimbel, S.M.; Mallory, D.E.; Maaswinkel, H.; Spritzer, S.D.; Sand, J.A.; Li, L.; Hyde, D.R.; Stenkamp, D.L. Ganglion cell regeneration following whole-retina destruction in zebrafish. Dev. Neurobiol. 2008, 68, 166-181. [CrossRef] [PubMed]

8. Lindsey, A.E.; Powers, M.K. Visual behavior of adult goldfish with regenerating retina. Vis. Neurosci. 2007, 24, 247-255. [CrossRef]

9. Mensinger, A.F.; Powers, M.K. Visual function in regenerating teleost retina following cytotoxic lesioning. Vis. Neurosci. 1999, 16, 241-251. [CrossRef] [PubMed]

10. Powell, C.; Grant, A.; Cornblath, E.; Goldman, D. Analysis of DNA methylation reveals a partial reprogramming of the Muller glia genome during retina regeneration. Proc. Natl. Acad. Sci. USA 2013, 110, 19814-19819. [CrossRef] [PubMed] 
11. Ramachandran, R.; Fausett, B.V.; Goldman, D. Ascl1a regulates Muller glia dedifferentiation and retinal regeneration through a Lin-28-dependent, let-7 microRNA signalling pathway (vol 12, pg 1101, 2010). Nat. Cell Biol. 2015, 17, 532. [CrossRef] [PubMed]

12. Fausett, B.V.; Goldman, D. A role for alpha1 tubulin-expressing Muller glia in regeneration of the injured zebrafish retina. J. Neurosci. 2006, 26, 6303-6313. [CrossRef]

13. Qin, Z.; Barthel, L.K.; Raymond, P.A. Genetic evidence for shared mechanisms of epimorphic regeneration in zebrafish. Proc. Natl. Acad. Sci. USA 2009, 106, 9310-9315. [CrossRef] [PubMed]

14. Nagashima, M.; Barthel, L.K.; Raymond, P.A. A self-renewing division of zebrafish Muller glial cells generates neuronal progenitors that require N-cadherin to regenerate retinal neurons. Development 2013, 140, 4510-4521. [CrossRef]

15. Kassen, S.C.; Ramanan, V.; Montgomery, J.E.; Burket, C.T.; Liu, C.-G.; Vihtelic, T.S.; Hyde, D.R. Time course analysis of gene expression during light-induced photoreceptor cell death and regeneration in albino zebrafish. Dev. Neurobiol. 2007, 67, 1009-1031. [CrossRef]

16. Reichenbach, A.; Bringmann, A. Glia of the human retina. Glia 2020, 68, 768-796. [CrossRef]

17. Turner, D.L.; Cepko, C.L. A common progenitor for neurons and glia persists in rat retina late in development. Nature 1987, 328, 131-136. [CrossRef]

18. Jadhav, A.P.; Roesch, K.; Cepko, C.L. Development and neurogenic potential of Muller glial cells in the vertebrate retina. Prog. Retin. Eye Res. 2009, 28, 249-262. [CrossRef]

19. Jadhav, A.P.; Cho, S.-H.; Cepko, C.L. Notch activity permits retinal cells to progress through multiple progenitor states and acquire a stem cell property. Proc. Natl. Acad. Sci. USA 2006, 103, 18998-19003. [CrossRef]

20. Furukawa, T.; Mukherjee, S.; Bao, Z.-Z.; Morrow, E.; Cepko, C.L. rax, Hes1, and notch1 promote the formation of Muller glia by postnatal retinal progenitor cells. Neuron 2000, 26, 383-394. [CrossRef]

21. Goureau, O.; Rhee, K.D.; Yang, X.-J. Ciliary neurotrophic factor promotes muller glia differentiation from the postnatal retinal progenitor pool. Dev. Neurosci. 2004, 26, 359-370. [CrossRef]

22. Bhattacharya, S.; Das, A.V.; Mallya, K.B.; Ahmad, L. Ciliary neurotrophic factor-mediated signaling regulates neuronal versus glial differentiation of retinal stem cells/progenitors by concentration-dependent recruitment of mitogen-activated protein kinase and Janus kinase-signal transducer and activator of transcription pathways in conjunction with Notch signaling. Stem Cells 2008, $26,2611-2624$

23. Sidman, R.L. Histogenesis of Mouse Retina Studied with Thymidine-H-3. Anat. Record 1960, 136, $276-277$.

24. Reichenbach, A.; Bringmann, A. New functions of Muller cells. Glia 2013, 61, 651-678. [CrossRef]

25. Bringmann, A.; Grosche, A.; Pannicke, T.; Reichenbach, A. GABA and Glutamate Uptake and Metabolism in Retinal Glial (Muller) Cells. Front. Endocrinol. 2013, 4, 48. [CrossRef]

26. Biedermann, B.; Biedermann, A.; Franze, K.; Faude, F.; Wiedemann, P.; Reichenbach, A. GABA(A) receptors in Muller glial cells of the human retina. Glia 2004, 46, 302-310. [CrossRef]

27. Brew, H.; Attwell, D. Electrogenic Glutamate Uptake Is a Major Current Carrier in the Membrane of Axolotl Retinal Glial-Cells. Nature 1987, 327, 707-709. [CrossRef]

28. Rauen, T.; Taylor, W.R.; Kuhlbrodt, K.; Wiessner, M. High-affinity glutamate transporters in the rat retina: A major role of the glial glutamate transporter GLAST-1 in transmitter clearance. Cell Tissue Res. 1998, 291, 19-31. [CrossRef]

29. Pow, D.V.; Robinson, S.R. Glutamate in Some Retinal Neurons Is Derived Solely from Glia. Neuroscience 1994, 60, 355-366. [CrossRef]

30. Hasegawa, H.; Ma, T.; Skach, W.; Matthay, A.M.; Verkman, A.S. Molecular cloning of a mercurial-insensitive water channel expressed in selected water-transporting tissues. J. Biol. Chem. 1994, 269, 5497-5500. [CrossRef]

31. Hasegawa, H.; Ma, T.; Skach, W.; Matthay, A.M.; Verkman, A.S. Immunogold evidence suggests that coupling of K+ siphoning and water transport in rat retinal Muller cells is mediated by a coenrichment of Kir4.1 and AQP4 in specific membrane domains. Glia 1999, 26, 47-54.

32. Hasegawa, H.; Ma, T.; Skach, W.; Matthay, A.M.; Verkman, A.S. Role of retinal glial cells in neurotransmitter uptake and metabolism. Neurochem. Int. 2009, 54, 143-160.

33. Newman, E.A. A physiological measure of carbonic anhydrase in Muller cells. Glia 1994, 11, 291-299. [CrossRef]

34. Tout, S.; Chan-Ling, T.; Holländer, H.; Stone, J. The role of Muller cells in the formation of the blood-retinal barrier. Neuroscience 1993, 55, 291-301. [CrossRef]

35. Choi, Y.K.; Kim, K.W. Blood-neural barrier: Its diversity and coordinated cell-to-cell communication. BMB Rep. 2008, 41, 345-352. [CrossRef]

36. Metea, M.R.; Newman, E.A. Glial cells dilate and constrict blood vessels: A mechanism of neurovascular coupling. J. Neurosci. 2006, 26, 2862-2870. [CrossRef]

37. Bernardos, R.; Barthel, L.K.; Meyers, J.R.; Raymond, P.A. Late-stage neuronal progenitors in the retina are radial Muller glia that function as retinal stem cells. J. Neurosci. 2007, 27, 7028-7040. [CrossRef]

38. Lawrence, J.M.; Singhal, S.; Bhatia, B.; Keegan, D.J.; Reh, T.A.; Luthert, P.J.; Khaw, P.T.; Limb, G.A. MIO-M1 cells and similar Muller glial cell lines derived from adult human retina exhibit neural stem cell characteristics. Stem Cells 2007, 25, 2033-2043. [CrossRef]

39. Lawrence, J.M.; Singhal, S.; Bhatia, B.; Keegan, D.J.; Reh, T.A.; Luthert, P.J.; Khaw, P.T.; Limb, G.A. Human Muller Glia with Stem Cell Characteristics Differentiate into Retinal Ganglion Cell (RGC) Precursors In Vitro and Partially Restore RGC Function In Vivo Following Transplantation. Stem Cells Transl. Med. 2012, 1, 188-199. 
40. Jayaram, H.; Jones, M.F.; Eastlake, K.; Cottrill, P.B.; Becker, S.; Wiseman, J.; Khaw, P.T.; Limb, G.A. Transplantation of Photoreceptors Derived From Human Muller Glia Restore Rod Function in the P23H Rat. Stem Cells Transl. Med. 2014, 3, 323-333. [CrossRef]

41. Becker, S.; Singhal, S.; Jones, M.F.; Eastlake, K.; Cottrill, P.B.; Jayaram, H.; Limb, G.A. Acquisition of RGC phenotype in human Muller glia with stem cell characteristics is accompanied by upregulation of functional nicotinic acetylcholine receptors. Mol. Vis. 2013, 19, 1925-1936.

42. Kiyama, T.; Li, H.; Gupta, M.; Lin, Y.-P.; Chuang, A.Z.; Otteson, D.; Wang, S.W. Distinct neurogenic potential in the retinal margin and the pars plana of mammalian eye. J. Neurosci. 2012, 32, 12797-12807. [CrossRef]

43. Jayakody, S.A.; Cordero, A.G.; Ali, R.; Pearson, R.A. Cellular strategies for retinal repair by photoreceptor replacement. Prog. Retin. Eye Res. 2015, 46, 31-66. [CrossRef] [PubMed]

44. Salero, E.; Blenkinsop, T.A.; Corneo, B.; Harris, A.; Rabin, D.; Stern, J.H.; Temple, S. Adult Human RPE Can Be Activated into a Multipotent Stem Cell that Produces Mesenchymal Derivatives. Cell Stem Cell 2012, 10, 88-95. [CrossRef] [PubMed]

45. Wang, S.Z.; Yan, R.T. The Retinal Pigment Epithelium: A Convenient Source of New Photoreceptor cells? J. Ophthalmic Vis. Res. 2014, 9, 83-93. [PubMed]

46. Dyer, M.A.; Cepko, C.L. Control of Muller glial cell proliferation and activation following retinal injury. Nat. Neurosci. 2000, 3, 873-880. [CrossRef]

47. Bringmann, A.; Iandiev, I.; Pannicke, T.; Wurm, A.; Hollborn, M.; Wiedemann, P.; Osborne, N.N.; Reichenbach, A. Cellular signaling and factors involved in Muller cell gliosis: Neuroprotective and detrimental effects. Prog. Retin. Eye Res. 2009, 28, 423-451. [CrossRef]

48. Bringmann, A.; Iandiev, I.; Pannicke, T.; Wurm, A.; Hollborn, M.; Wiedemann, P.; Osborne, N.N.; Reichenbach, A. Potential for neural regeneration after neurotoxic injury in the adult mammalian retina. Proc. Natl. Acad. Sci. USA 2004, 101, 13654-13659.

49. Karl, M.; Hayes, S.; Nelson, B.R.; Tan, K.; Buckingham, B.; Reh, T.A. Stimulation of neural regeneration in the mouse retina. Proc. Natl. Acad. Sci. USA 2008, 105, 19508-19513. [CrossRef]

50. Wan, J.; Zheng, H.; Chen, Z.-L.; Xiao, H.-L.; Shen, Z.-J.; Zhou, G.-M. Preferential regeneration of photoreceptor from Muller glia after retinal degeneration in adult rat. Vis. Res. 2008, 48, 223-234. [CrossRef]

51. Osakada, F.; Ooto, S.; Akagi, T.; Mandai, M.; Akaike, A.; Takahashi, M. Wnt signaling promotes regeneration in the retina of adult mammals. J. Neurosci. 2007, 27, 4210-4219. [CrossRef] [PubMed]

52. Angbohang, A.; Wu, N.; Charalambous, T.; Eastlake, K.; Lei, Y.; Kim, Y.S.; Sun, X.H.; Limb, G.A. Downregulation of the Canonical WNT Signaling Pathway by TGFbeta1 Inhibits Photoreceptor Differentiation of Adult Human Muller Glia with Stem Cell Characteristics. Stem Cells Dev. 2016, 25, 1-12. [CrossRef] [PubMed]

53. Giannelli, S.G.; Demontis, G.C.; Pertile, G.; Rama, P.; Broccoli, V. Adult human Muller glia cells are a highly efficient source of rod photoreceptors. Stem Cells 2011, 29, 344-356. [CrossRef] [PubMed]

54. Joly, S.; Pernet, V.; Samardzija, M.; Grimm, C. PAX6-Positive Muller Glia Cells Express Cell Cycle Markers but Do Not Proliferate After Photoreceptor Injury in the Mouse Retina. Glia 2011, 59, 1033-1046. [CrossRef] [PubMed]

55. Löffler, K.; Schäfer, P.; Völkner, M.; Holdt, T.; Karl, M.O. Age-dependent Muller glia neurogenic competence in the mouse retina. Glia 2015, 63, 1809-1824. [CrossRef] [PubMed]

56. Ueki, Y.; Reh, T.A. EGF stimulates Muller glial proliferation via a BMP-dependent mechanism. Glia 2013, 61, 778-789. [CrossRef] [PubMed]

57. Close, J.L.; Liu, J.; Gumuscu, B.; Reh, T.A. Epidermal growth factor receptor expression regulates proliferation in the postnatal rat retina. Glia 2006, 54, 94-104. [CrossRef]

58. Close, J.L.; Gumuscu, B.; Reh, T.A. Retinal neurons regulate proliferation of postnatal progenitors and Muller glia in the rat retina via TGF beta signaling. Development 2005, 132, 3015-3026. [CrossRef]

59. Takeda, M.; Takamiya, A.; Jiao, J.-W.; Cho, K.-S.; Trevino, S.G.; Matsuda, T.; Chen, D.F. alpha-Aminoadipate induces progenitor cell properties of Muller glia in adult mice. Investig. Ophthalmol. Vis. Sci. 2008, 49, 1142-1150. [CrossRef]

60. Fausett, B.V.; Gumerson, J.D.; Goldman, D. The proneural basic helix-loop-helix gene ascl1a is required for retina regeneration. J. Neurosci. 2008, 28, 1109-1117. [CrossRef]

61. Pollak, J.; Wilken, M.S.; Ueki, Y.; Cox, K.E.; Sullivan, J.M.; Taylor, R.J.; Levine, E.M.; Reh, T.A. ASCL1 reprograms mouse Muller glia into neurogenic retinal progenitors. Development 2013, 140, 2619-2631. [CrossRef]

62. Wan, J.; Zheng, H.; Xiao, H.-L.; She, Z.-J.; Zhou, G.-M. Sonic hedgehog promotes stem-cell potential of Muller glia in the mammalian retina. Biochem. Biophys. Res. Commun. 2007, 363, 347-354. [CrossRef] [PubMed]

63. MacLaren, R.E. Development and role of retinal glia in regeneration of ganglion cells following retinal injury. Br. J. Ophthalmol. 1996, 80, 458-464. [CrossRef] [PubMed]

64. Jorstad, N.L.; Wilken, M.S.; Grimes, W.N.; Wohl, S.G.; VandenBosch, L.S.; Yoshimatsu, T.; Wong, R.O.; Rieke, F.; Reh, T.A. Stimulation of functional neuronal regeneration from Muller glia in adult mice. Nature 2017, 548, 103-107. [CrossRef] [PubMed]

65. Ghai, K.; Zelinka, C.; Fischer, A.J. Notch signaling influences neuroprotective and proliferative properties of mature Muller glia. J. Neurosci. 2010, 30, 3101-3112. [CrossRef]

66. Fischer, A.J.; Reh, T.A. Exogenous growth factors stimulate the regeneration of ganglion cells in the chicken retina. Dev. Biol. 2002, 251, 367-379. [CrossRef]

67. Fischer, A.J.; McGuire, C.R.; Dierks, B.D.; Reh, T.A. Insulin and fibroblast growth factor 2 activate a neurogenic program in Muller glia of the chicken retina. J. Neurosci. 2002, 22, 9387-9398. [CrossRef] 
68. Fischer, A.J.; Scott, M.A.; Tuten, W. Mitogen-activated protein kinase-signaling stimulates Muller glia to proliferate in acutely damaged chicken retina. Glia 2009, 57, 166-181. [CrossRef] [PubMed]

69. Fischer, A.J.; Reh, T.A. Muller glia are a potential source of neural regeneration in the postnatal chicken retina. Nat. Neurosci. 2001, 4, 247-252. [CrossRef] [PubMed]

70. Gu, D.; Wang, S.; Zhang, S.; Zhang, P.; Zhou, G. Directed transdifferentiation of Muller glial cells to photoreceptors using the sonic hedgehog signaling pathway agonist purmorphamine. Mol. Med. Rep. 2017, 16, 7993-8002. [CrossRef]

71. Yao, K.; Qiu, S.; Wang, Y.V.; Park, S.J.H.; Mohns, E.J.; Mehta, B.; Liu, X.; Chang, B.; Zenisek, D.; Crair, M.C.; et al. Restoration of vision after de novo genesis of rod photoreceptors in mammalian retinas. Nature 2018, 560, 484-488. [CrossRef]

72. Yao, K.; Qiu, S.; Tian, L.; Snider, W.D.; Flannery, J.; Schaffer, D.V.; Chen, B. Wnt Regulates Proliferation and Neurogenic Potential of Muller Glial Cells via a Lin28/let-7 miRNA-Dependent Pathway in Adult Mammalian Retinas. Cell Rep. 2016, 17, 165-178. [CrossRef] [PubMed]

73. Wohl, S.G.; Hooper, M.J.; Reh, T.A. MicroRNAs miR-25, let-7 and miR-124 regulate the neurogenic potential of Muller glia in mice. Development 2019, 146, dev179556. [CrossRef]

74. Ji, H.-P.; Xiong, Y.; Song, W.-T.; Zhang, E.-D.; Gao, Z.-L.; Yao, F.; Su, T.; Zhou, R.-R.; Xia, X.-B. MicroRNA-28 potentially regulates the photoreceptor lineage commitment of Muller glia-derived progenitors. Sci. Rep. 2017, 7, 11374. [CrossRef]

75. Sanges, D.; Romo, N.; Simonte, G.; Vicino, U.D.; Tahoces, A.D.; Fernández, E.; Cosma, M.P. Wnt/beta-catenin signaling triggers neuron reprogramming and regeneration in the mouse retina. Cell Rep. 2013, 4, 271-286. [CrossRef] [PubMed]

76. Sanges, D.; Simonte, G.; Di Vicino, U.; Romo, N.; Pinilla, I.; Nicolás, M.; Cosma, M.P. Reprogramming Muller glia via in vivo cell fusion regenerates murine photoreceptors. J. Clin. Investig. 2016, 126, 3104-3116. [CrossRef] [PubMed]

77. Nishimura, K.; Fukuda, A.; Hisatake, K. Mechanisms of the Metabolic Shift during Somatic Cell Reprogramming. Int. J. Mol. Sci. 2019, 20, 2254. [CrossRef]

78. Naik, P.P.; Birbrair, A.; Bhutia, S.K. Mitophagy-driven metabolic switch reprograms stem cell fate. Cell. Mol. Life Sci. 2019, 76, 27-43. [CrossRef]

79. Palazzo, I.; Deistler, K.; Hoang, T.V.; Blackshaw, S.; Fischer, A.J. NF-kappaB signaling regulates the formation of proliferating Muller glia-derived progenitor cells in the avian retina. Development 2020, 147, dev183418. [CrossRef]

80. Takahashi, K.; Yamanaka, S. Induction of pluripotent stem cells from mouse embryonic and adult fibroblast cultures by defined factors. Cell 2006, 126, 663-676. [CrossRef]

81. Slembrouck-Brec, A.; Rodrigues, A.; Rabesandratana, O.; Gagliardi, G.; Nanteau, C.; Fouquet, S.; Thuret, G.; Reichman, S.; Orieux, G.; Goureau, O. Reprogramming of Adult Retinal Muller Glial Cells into Human-Induced Pluripotent Stem Cells as an Efficient Source of Retinal Cells. Stem Cells Int. 2019, 2019, 7858796. [CrossRef]

82. Chung, S.H.; Shen, W.; Davidson, K.C.; Pébay, A.; Wong, R.C.-B.; Yau, B.; Gillies, M. Differentiation of Retinal Glial Cells From Human Embryonic Stem Cells by Promoting the Notch Signaling Pathway. Front. Cell. Neurosci. 2019, 13, 527. [CrossRef] [PubMed]

83. Del Debbio, C.B.; Balasubramanian, S.; Parameswaran, S.; Chaudhuri, A.; Qiu, F.; Ahmad, I. Notch and Wnt signaling mediated rod photoreceptor regeneration by Muller cells in adult mammalian retina. PLoS ONE 2010, 5, e12425. [CrossRef] [PubMed] 